\title{
Differential sensitivity of the Brattleboro rat to glutamatergic and dopaminergic perturbation
}

Robert E. Lin, Lauren Ambler, Eddie N. Billingslea, Jimmy Suh, Monica Cho, Anthony Ciacci, Valerie Tatard-Leitman, Robert E. Featherstone and Steven J. Siegel

*Correspondence: siegels@med.mail.upenn.edu 1 CrossMark

Department of Psychiatry, Translational Neuroscience Program, School of Medicine, University of Pennsylvania, Philadelphia, PA.

\begin{abstract}
Background: The vasopressin deficient Brattleboro (BRAT) rats have behavioral impairments which mimic those seen in other schizophrenia models. However, the mechanism by which vasopressin produces these behavioral abnormalities is unclear. Notably, elevations in dopamine signaling as well as reductions in glutamatergic signaling have been associated with behavioral impairments consistent with those observed in the BRAT rats. Therefore, a potential mechanism for vasopressin induces behavioral abnormalities could be through modulation of dopamine or glutamate signaling. Consequently, the aim of this study was to assess the modulatory function of vasopressin on dopamine and NMDA signaling.

Methods: Single intraperitoneal injection of amphetamine $(0.5 \mathrm{mg} / \mathrm{kg})$, a dopamine agonist, and MK801 (0.25 mg/kg), a NMDA antagonist, were used to assess vasopressin (VP) modulatory activity on dopaminergic and glutamatergic pre-pulse inhibition of startle (PPI), social interaction and auditory event related potential (ERPs) impairments in BRAT and littermate control WT rats.

Results: MK801-induced impairments were consistent and not significantly different between WT and BRAT rats suggesting minimal modulatory activity of vasopressin on NMDA signaling. In contrast, amphetamine-induced deficits were genotype dependent. In control animals, amphetamine caused a statistically significant deficit in PPI and social interaction whereas there was no effect in BRAT rats. Conversely, ERP components were unaltered in control rats, whereas N40 amplitude, evoked gamma power, and gamma signal to noise ratio were all elevated in BRAT rats.

Conclusions: The ERP component analyses of BRAT rats treated with amphetamine suggest modulation of auditory information processing through interplay between dopaminergic and vasopressin. However, the behavioral and electrophysiological evidence presented here also suggest that vasopressin does not modulate glutamatergic signaling through NMDA receptors. Further evidence in necessary to determine the interaction between vasopressin and dopamine signaling and future studies are necessary to comprehend glutamatergic interactions with vasopressin that are not NMDA-mediated.
\end{abstract}

Keywords: Brattleboro, schizophrenia, ERP, PPI, social, vasopressin

\section{Introduction}

Schizophrenia is a disabling condition which is characterized by abnormal information processing accompanied with emotional disengagement. These deficits are manifested in conjunction with positive symptoms such as delusions and hallucinations as well as negative symptoms including anhedonia, asociality, and avolition. Although the etiology of schizophrenia is unclear, there is evidence supporting genetic, environmental, and developmental vulnerabilities to disease [1-6]. Current evidence supports two main theories regarding the pathophysiology of schizophrenia, which are the glutamate and dopamine hypotheses [7-9].

The dopamine hypothesis of schizophrenia originated from evidence that excess DA transmission was associated with schizophrenia and inhibition could be used to treat psychosis [10-14]. Further clinical studies provide evidence that the effective dose of antipsychotic drugs is related to their affinity to dopamine type 2 receptors [11-14]. Additionally, neurochemical imaging studies have shown that schizophrenia patients have elevated dopamine receptor availability in certain brain regions [15]. One current interpretation of the dopamine hypothesis is that presynaptic dopamine dysregulation is a common mechanism leading to psychosis in schizophrenia [8]. Alternatively, another review suggests that functional supersensitivity of postsynaptic dopamine signaling is a common mechanism leading to positive symptoms seen in schizophrenia [16]. Although the preponderance of evidence demonstrates a crucial role of abnormal dopamine signaling in schizophrenia, there is also growing evidence for the role other neurotransmitter systems.

The glutamate system has garnered interest because NMDA receptor antagonists such as PCP and ketamine were noted to cause symptoms similar to those seen in patients with various psychological disorders such as schizophrenia [17]. Since the 1950s, the use of NMDA antagonists as a method of modeling schizophrenia in animals has been well established 
Lin et al. Journal of Psychiatry and Brain Functions 2014,

http://www.hoajonline.com/journals/pdf/2055-3447-1-3.pdf

doi: 10.7243/2055-3447-1-3

[18]. For example, in 1959 the alanine analogue cycloserine, which is a NMDA receptor partial agonist at low doses and antagonist at high doses, induced or exacerbated psychotic symptoms [19]. Numerous studies have provided support that NMDA antagonists can induce behavioral and cognitive abnormalities in animal models that are similar to a subset of symptoms found in schizophrenia [20]. Additionally, ketamine produces an exacerbation of symptoms in schizophrenia patients [21]. These studies provide evidence supporting an essential role of glutamate signaling in schizophrenia. Furthermore, dopaminergic and glutamatergic signaling abnormalities likely do not act independently in contributing to the pathophysiology of schizophrenia.

The neuropeptide vasopressin (VP) has also been implicated in schizophrenia, as evidenced by the association of a single nucleotide polymorphism in the VP gene with schizophrenia [22]. VP is also involved in behavioral outcomes important in the etiology of schizophrenia such as learning and memory, aggression, and sociality [23]. In addition, both glutamate and VP antagonism have been associated with negative symptoms of schizophrenia, suggesting a potential interaction between glutamate and VP signaling in the brain [24-26]. Moreover, there is evidence that VP activity in the hypothalamus may be regulated by glutamatergic signaling [22]. Similarly, VP signaling may also modulate dopaminergic activity as illustrated by an increase in dopamine type 2 receptors in the striatum of VP deficient rats [27-29]. Collectively, the interactive relationship between VP and the dopamine and glutamate systems provide a rationale to consider agents that alter VP activity as potential candidates for pharmacological interventions in schizophrenia.

Previous studies investigating the use of VP analogs in schizophrenia have yielded mixed results. DDAVP, a synthetic VP agonist, produced improvements in negative symptom profiles in schizophrenia patients [24,27-30]. However, DDAVP did not improve cognitive performance in humans with amnesia [31]. Similarly, intranasal VP enhanced emotion recognition and memory encoding in healthy male human subjects $[32,33]$. Furthermore, VP is critically important in social recognition, social communication, and aggression in other mammalian species suggesting good translatability to human populations [34]. Although VP and its analogs can improve social performance in humans, it results in peripheral side effects associated with anti-diuretic effects as well as an increased activation of the HPA axis and the resulting stress

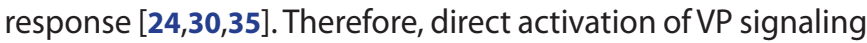
is limited as a treatment for schizophrenia. Alternatively, novel therapeutic targets with less peripheral adverse effects may be developed by first understanding the mechanism mediating the pro-social effects of VP.

Brattleboro (BRAT) rats have a mutation in the VP gene, which prevents appropriate formation of the protein, resulting in systemic loss of VP. In the brain, VP receptors are present primarily as $\mathrm{V} 1 \mathrm{a}$ and $\mathrm{V} 1 \mathrm{~b}$ receptors with $\mathrm{V} 1 \mathrm{a}$ receptors being predominant. Autoradiography studies have indicated high levels of binding in the choroid plexus, lateral septum, bed nucleus of stria terminalis, accumbens nucleus, central nucleus of amygdala, stigmoid hypothalamic nucleus, suprachiasmatic nucleus, arcuate nucleus, nucleus of the solitary tract, area postrema and parts of the hippocampus, thalamus, superior colliculus, and inferior olivary nuclei [36]. V1b receptors are found in the hypothalamus, amygdala, cerebellum, and areas with a leaky blood brain barrier [37]. The VP deficit in BRAT rats produces impairments in several behavioral domains consistent with schizophrenia such as increased startle, impaired cognitive performance, and reduced social function with mixed results regarding hyperactivity and anxiety-related phenotypes [27,38-43]. These VP-induced deficits encompass behaviors associated with dopaminergic and glutamatergic dysfunction. Not surprisingly, BRAT rats have alterations in dopaminergic and glutamatergic function. For example, BRAT rats have decreased dopamine availability in the frontal cortex as well as upregulation of striatal dopamine-2 receptors $[29,44]$. Additionally, increased concentration of glutamate has been reported in the forebrain of BRAT rats [45]. Therefore, the VP deficiency in BRAT rats provides an opportunity to gain further understanding of the potential interactions between glutamatergic, dopaminergic and vasopressin systems.

In this paper, we use BRAT rats to determine the extent to which alterations in VP signaling affect behavioral and electrophysiological response to the indirect dopamine agonist amphetamine and the NMDA receptor antagonist MK801. We propose that BRAT rats will have enhanced responses to both dopaminergic and glutamatergic perturbations across behavioral and electrophysiological measures related to schizophrenia.

\section{Methods \\ Animals}

BRAT rats were bred at the University of Pennsylvania from two heterozygous breeding pairs purchased from the Rat Resource \& Research Center (RRRC, Columbia, MO). All subsequent rats were bred from heterozygous pairs in an Association for Assessment and Accreditation of Laboratory Animal Care-accredited animal facility and housed two to three per cage until electrode implantation and single-housed thereafter in a light- and temperature-controlled room. Light cycle was between $6 \mathrm{am}-6 \mathrm{pm}$ and water and standard rodent chow were available ad libitum. Experiments were conducted in male 300-400g BRAT rats and their littermate controls (WT) at the University of Pennsylvania during the light phase between 9:00 AM and 5:00 PM. Genotypes were determined by sequencing DNA extracted from tail snips for the Avp gene according to protocol provided (RRRC, Columbia, $\mathrm{MO}$ ). Separate sets of animals were used to perform startle/ $\mathrm{PPI}$, social interaction/USV, and electrophysiological testing. All protocols were performed in accordance with University Laboratory Animal Resources guidelines and were approved 
by the Institutional Animal Care and Use Committee at the University of Pennsylvania (Protocol \#804371). The mean weight for wild type animals was $396.6 \pm 64.8$ and that of BRAT rats was $368 \pm 72.1(p=0.37)$.

\section{Drugs}

Behavioral and electrophysiological testing was performed with saline, $0.25 \mathrm{mg} / \mathrm{kg}$ MK801, or $0.5 \mathrm{mg} / \mathrm{kg}$ amphetamine. The doses used were based on previous locomotor activity studies where each drug tested produced similar levels of hyperactivity (Data not shown). MK801 (Sigma) was dissolved in a $1.0 \mathrm{mg} / \mathrm{ml}$ stock solution which was diluted to a 0.25 $\mathrm{mg} / \mathrm{ml}$ working solution on the day of experimentation. Amphetamine was also dissolved in $0.9 \%$ saline to a stock solution of $10 \mathrm{mg} / \mathrm{ml}$ and diluted to a $0.5 \mathrm{mg} / \mathrm{ml}$ working solution on the day of testing. Rats were weighed prior to testing and drugs were administered in a volume of $1 \mathrm{ml} / \mathrm{kg}$ via intraperitoneal injection 15 minutes before tasks.

\section{Startle and prepulse inhibition}

Startle and prepulse inhibition (PPI) of acoustic startle was assessed (WT $n=7$, BRAT $n=6$ ) using a startle response system (San Diego Instruments, San Diego, CA, USA). Rats were acclimated to the chamber for 5 minutes with background white noise (65 dB) which was also played throughout the test session. Auditory startling stimuli were delivered by a speaker mounted inside the chamber. Startle was detected by a piezoelectric accelerometer mounted beneath the platform. Tones were presented randomly ten times with a randomized inter-trial interval ranging from 10 to 20 seconds. Startle was measured in response to 40-millisecond white noise pulses (tones) between 90-120 dB with $5 \mathrm{~dB}$ increments. PPI was done using ten prepulse trials consisted of a 20-millisecond pulse at $69 \mathrm{~dB}$ followed by a 40-millisecond pulse of $120 \mathrm{~dB}$ with an interstimulus interval (ISI) of 100ms [46]. Prepulse inhibition was calculated as the percent difference in startle units following the prepulse/startle pair as compared to the startle tone alone.

\section{Social interaction and ultrasonic vocalizations}

Two previously unpaired rats of the same sex and genotype (WT $n=6$, BRAT $n=6$, pairs) were placed in the center of a $32 "(\mathrm{~W}) \times 18^{\prime \prime}(\mathrm{D}) \times 12$ " $(\mathrm{H})$ plastic chamber with no bedding and video was recorded for 5 minutes in low light. Ultrasonic vocalizations (USVs) were recorded simultaneously using an ultrasonic range detector placed $60 \mathrm{~cm}$ above the chamber (Pettersson Electronik D940 Ultrasound Detector, Uppsala, Sweden). The microphone was interfaced with a Micro1401 data acquisition unit (CED) sampling at $250 \mathrm{kHz}$ recorded through Spike2 software (CED). The chamber was cleaned with $70 \%$ ethanol between recordings.

The video was manually scored for the amount of time the animals spent interacting. A social interaction was considered to be any time the snout of one animal was in direct contact with the other. Vocalizations were counted manually with the investigator blinded to genotype and drug conditions.

\section{Event related potentials \\ Electrode implantation}

Animals (WT $n=10$, BRAT $n=10$ ) underwent stereotaxic implantation of three channel electrodes (PlasticsOne Inc., Roanoke, VA) unilaterally placed in the prelimbic cortex (rat prefrontal cortical area) under isoflurane anesthesia, $(3.2 \mathrm{~mm}$ anterior, $1 \mathrm{~mm}$ lateral, and $4 \mathrm{~mm}$ deep relative to bregma) and referenced to the cerebellum ( $2 \mathrm{~mm}$ posterior, $2 \mathrm{~mm}$ lateral and $2 \mathrm{~mm}$ deep, relative to lambda) as previously reported [47-50]. Since the positive and negative electrodes are located far apart from one another, activity recorded using this configuration extends far beyond the localized field generated within the prelimbic cortex, and therefore reflects brain activity across a widespread area similar to a human EEG recording. Histological verification of electrode placement was performed following the completion of experiments. Dental cement and ethyl cyanoacrylate (Elmers, Columbus, $\mathrm{OH}$ ) were used to secure the electrode pedestal to the skull. Procedures were consistent with descriptions

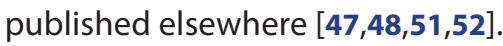

\section{Recording}

After a 1 week recovery period, EEG was recorded during the presentation of an auditory task. The auditory task consisted of a single click paradigm with presentation of a $9 \mathrm{kHz}$ tone $(10 \mathrm{~ms}, 85 \mathrm{~dB})$ at a 4 second inter-stimulus interval 200 times against $70 \mathrm{~dB}$ of background noise. EEG was recorded with a sampling rate of $1667 \mathrm{~Hz}$ and band-pass filtered between 1 and $500 \mathrm{~Hz}$ during collection. Stimuli were generated by Power 1401 hardware and Spike 6 software (Cambridge Electronic Design, Cambridge, UK) and were delivered through speakers attached to the cage top. All recordings were performed in a plastic cage 7"(W)x11"(D)x5"(H) with standard bedding, which was placed in a Faraday cage 15 minutes before stimulus onset.

\section{Analysis}

For each animal, individual trials were rejected for movement artifact defined by two times the root mean square of the amplitude per rat. Average waves were created from 1000ms pre-stimulus to $1000-m s$ post-stimulus time. The N40 component was defined as the maximum negative deflection between 25 and $60 \mathrm{~ms}$. Power analysis was performed using EEGLAB (Schwartz Center for Computational Neuroscience). Event-related gamma (30-80 Hz and 0-60 ms) power were calculated using Morlet wavelets in 116 logarithmically spaced frequency bins between 4 and $120 \mathrm{~Hz}$, with wavelet cycle numbers ranging from 2 to 10 .

\section{Statistics}

All statistics were performed for each paradigm with the Statistica software package (StatSoft, Inc., Tulsa, OK) using 
Lin et al. Journal of Psychiatry and Brain Functions 2014,

a repeated measures analysis of variance (rmANOVA) with genotype as the categorical variable (WT vs. BRAT) and drug condition (saline, amphetamine, MK801) as the repeated variable within each measure. Comparisons were made between WT and BRAT rats following saline and either MK801 or amphetamine, such that each drug was compared to saline in a separate rmANOVA. All post hoc analyses were performed with Fisher Least Squared Differences (LSD).

\section{Results}

\section{Startle and PPI}

The startle response during saline conditions was elevated in the BRAT rats $\left(\mathrm{F}_{1,11}=9.11, \mathrm{p}=0.01\right)$ as previously reported [27]. The administration of MK801 prior to testing did not have an effect on startle response in the WT or BRAT groups $\left(F_{1,10}=0.45\right.$, $\mathrm{p}=0.52$ ). Fisher $\mathrm{LSD}$ post hoc analyses were explored to assess differential responses between WT and BRAT rats as this was the primary rationale for the study. There was no significant effect of MK801 on either WT (MS=8869.7, df=19.3, $p=0.31$ ) or BRAT rats (MS=8869.7, $\mathrm{df}=19.3, \mathrm{p}=0.91$ ), suggesting that the effect of the drug was similar among both groups. On the other hand, startle was reduced with amphetamine treatment $\left(F_{1,10}=10.05, p=0.01\right)$. Post hoc analysis indicated that the startle response in the WT rats was not reduced following amphetamine administration (MS=4920.7, $d f=17.9, p=0.18$ ), the startle response of the BRAT rats was significantly lower following amphetamine than saline (Figure 1A, MS= 4920.7, $d f=17.9, p=0.01$ ).

PPI was not different between WT and BRAT rats following saline administration $\left(F_{1,11}=0.17, p=0.69\right)$, as reported previously [44]. MK801 caused a significant reduction in PPI across both genotypes $\left(F_{1,11}=10.2, p=0.008\right)$. LSD post hoc analyses were explored to assess differential responses between WT and BRAT rats as this was the primary rationale for the study. There was a significant reduction of MK801 in $\mathrm{WT}(\mathrm{MS}=737.2, \mathrm{df}=22.0$, $\mathrm{p}=0.03$ ) and BRAT rats $(\mathrm{MS}=737.2, \mathrm{df}=22.0, \mathrm{p}=0.02)$, suggesting that the effect of the drug was similar between both groups. Similar to MK801, amphetamine also caused a reduction in PPI $\left(F_{1,11}=7.44, p=0.02\right)$. In order to determine differential response between the WT and BRAT, post hoc analysis of the genotype by amphetamine interaction indicated a reduction in PPI in WT rats (MS $=1561.6, \mathrm{df}=19.1, \mathrm{p}=0.01)$ but not in BRAT rats (Figure 1B, $M S=1561.6, d f=19.1, p=0.4$ ).

\section{Social interaction}

The time spent interacting following saline administration was decreased in the BRAT rats $\left(F_{1,10}=14.17, p=0.004\right)$ as previously reported [42]. The administration of MK801 did not produce any change in social interaction in the WT and BRAT groups $\left(\mathrm{F}_{1,20}=0.00066, \mathrm{p}=0.98\right)$. To assess differential response to MK801 post hoc analyses indicated no change in time spent interaction in WT (MS=250.7, $\mathrm{df}=20.0, \mathrm{p}=0.79$ ) or BRAT ( $M S=250.7, d f=20.0, p=0.82$ ). Similarly, the administration of amphetamine caused no overall drug effect $\left(F_{1,19}=1.37\right.$,

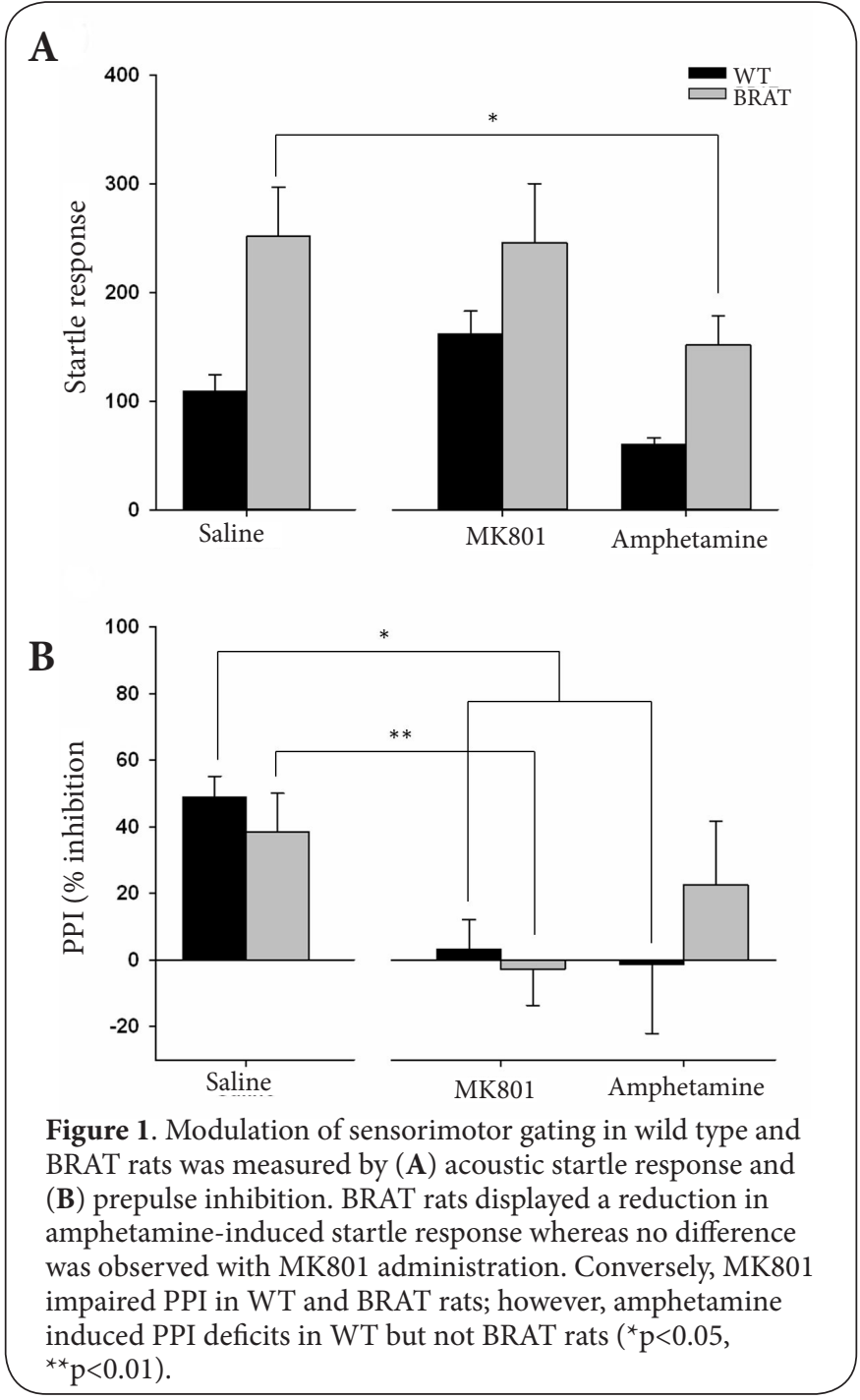

$\mathrm{p}=0.26)$. However, post hoc analysis to assess differential response revealed a significant reduction in social interactions in WT rats following amphetamine $(M S=128.4, d f=19, p=0.01$ ), whereas there was no such difference in the BRAT rats (Figure 2A, $M S=128.4, d f=19, p=0.28$ ).

There was no difference in the number of socially-induced USVs per minute between WT and BRAT rats following saline administration $\left(F_{1,10}=0.36, p=0.56\right)$. MK801 reduced the number of calls across both genotypes $\left(F_{1,19}=13.48, p=0.002\right)$. However, there was no difference in the extent to which MK801 reduced the number of calls between genotypes (MS=2189.3, $d f=20.0, p=0.04$ for $W T, p=0.006$ for BRAT). On the other hand, amphetamine administration did not produce a main effect across both groups $\left(F_{1,19}=1.17, p=0.29\right)$. Post hoc analysis revealed a significant increase in USVs among the BRAT rats following amphetamine $(\mathrm{MS}=4085.5, \mathrm{df}=29.0$, $\mathrm{p}=0.03$ ) whereas a significant reduction occurred in WT rats (Figure 2B, MS $=4085.5, \mathrm{df}=29.0, \mathrm{p}=0.03$ ). . This data indicates that during a social context there is a difference in USV 


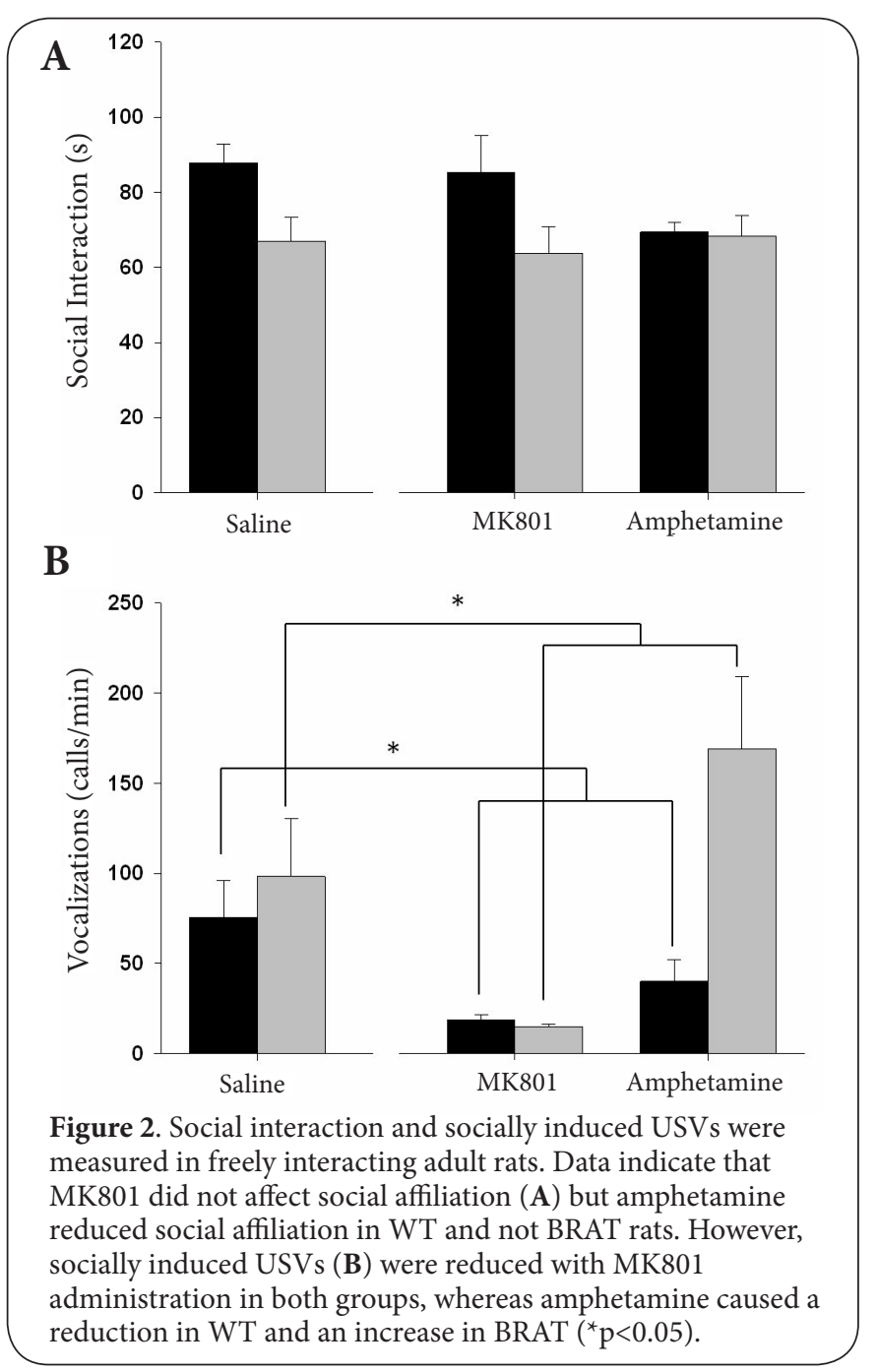

production between WT and BRAT rats with amphetamine treatment but not MK801.

\section{ERPs}

There was no difference in N40 amplitude between WT and BRAT rats during saline treatment, however there was a qualitative decrease in amplitude $\left(F_{1,18}=140, p=0.25\right)$. There was a reduction in N40 amplitude with MK801 treatment $\left(F_{2}\right.$ $\left.{ }_{34}=16.86, p=0.00001\right)$. Post hoc analysis revealed significant reductions in $\mathrm{N} 40$ amplitude in both $\mathrm{WT}(\mathrm{MS}=513.5, \mathrm{df}=33.3$, $p=0.006)$ and BRAT ( $M S=513.5, d f=33.3, p=0.03)$. Conversely, amphetamine did not produce any statistically significant effect on $\mathrm{N} 40$ amplitude across both genotypes examined $\left(F_{1,16}=0.35, p=0.56\right)$. Post hoc analysis of the amphetamine by genotype interaction indicate a significant increase in N40 amplitude in BRAT rats (MS=659.5, $\mathrm{df}=31.1, \mathrm{p}=0.02$ ) whereas there is no difference in response in the WT rats (Figure 3, $M S=659.5, d f=31.1, p=0.14$ ).

Time frequency measures were calculated in the gamma frequency band $(30-80 \mathrm{~Hz})$. Baseline gamma power was not

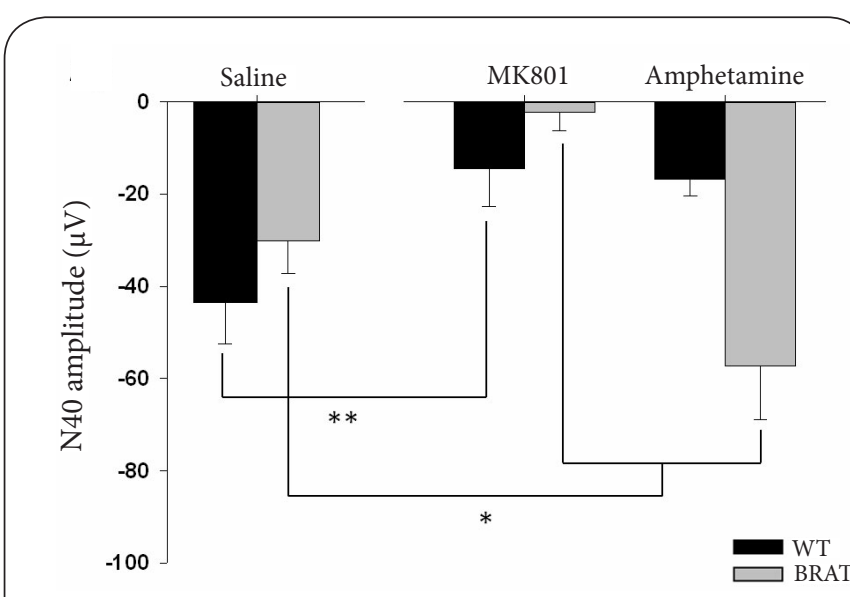

Figure 3. Event related potential (ERP) components in WT and BRAT rats were extracted and the N40 amplitude was reduced with MK801 treatment regardless of genotype. However, amphetamine enhanced N40 amplitude in BRAT but not WT rats $\left({ }^{*} \mathrm{p}<0.05,{ }^{* *} \mathrm{p}<0.001\right)$.

different following saline $\left(F_{1,18}=1.04, p=0.32\right)$. Administration of MK801 caused an increase in baseline gamma power $\left(F_{1}\right.$ $18=25.90, p=0.00008)$ which was consistent in the WT (MS=3.8, $\mathrm{df}=33.3, \mathrm{p}=0.01)$ and BRAT rats $(\mathrm{MS}=3.8, \mathrm{df}=33.3, \mathrm{p}=0.0003)$. There was no significant effect of amphetamine on baseline gamma power across genotypes $\left(F_{1,18}=2.39, p=0.14\right)$. Post hoc analyses indicated that there was a reduction in baseline power in BRAT rats ( $M S=6.95, d f=35.3, p=0.03$ ), which was not present among WT rats (Figure 4A, MS=6.95, df $=35.3, p=0.82$ ).

Evoked gamma power was not different between WT and BRAT rats following saline $\left(F_{1,17}=0.96, p=0.34\right)$. MK801 had no effect on evoked power across both groups $\left(F_{1,17}=1.51\right.$, $p=0.24, M S=0.02, d f=30.7, p=0.41$ for $W T, p=0.38$ for BRAT). Similarly, there was no effect of amphetamine on evoked gamma power across groups $\left(F_{1,14}=0.002, p=0.97\right)$. However, post hoc analysis of the genotype by amphetamine interaction revealed a trend for a reduction in evoked gamma power in WT ( $M S=0.02, d f=27.2, p=0.09$ ) and an increase in BRAT rats (Figure 4B, MS=0.02, $\mathrm{df}=27.2, \mathrm{p}=0.05$ ).

Gamma SNR was not different among WT and BRAT groups following saline $\left(F_{1,17}=1.00, p=0.33\right)$. The administration of MK801 did not alter gamma SNR $\left(\mathrm{F}_{1,17}=2.05, \mathrm{p}=0.17\right)$ and no effect was observed in WT (MS=0.0001, $d f=30.6, p=0.33$ ) and BRAT (MS $=0.0001, d f=30.6, p=0.32$ ). Likewise, amphetamine administration had no overall effect on gamma SNR $\left(F_{1,15}=0.37\right.$, $\mathrm{p}=0.55$ ). However, post hoc analysis indicated an increase in gamma $S N R$ in the BRAT rat $(M S=0.00001, d f=29.7$, $\mathrm{p}=0.02$ ) which was not present among WT rats (Figure $4 C$, $M S=0.00001, d f=29.7, p=0.16)$.

\section{Discussion}

The behavioral phenotypes of BRAT rats and other VP deficiency models have previously been studied leading to the idea that VP plays an important role in schizophrenia [27-29, 38-42, 53-58]. 


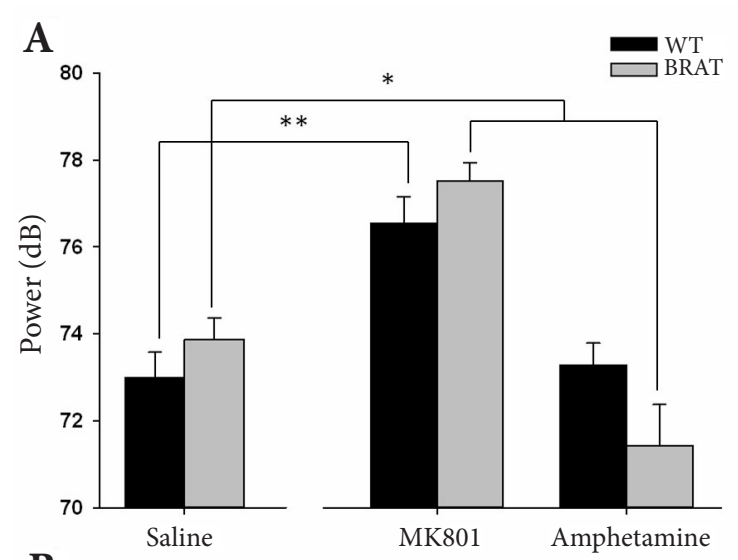

B

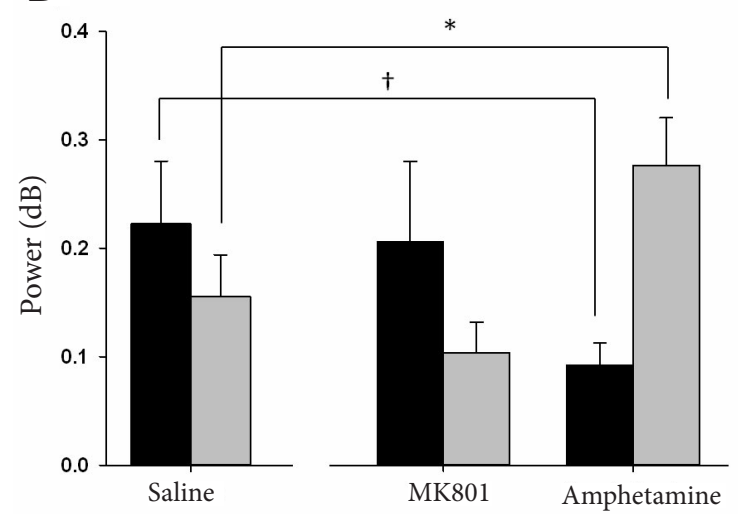

C

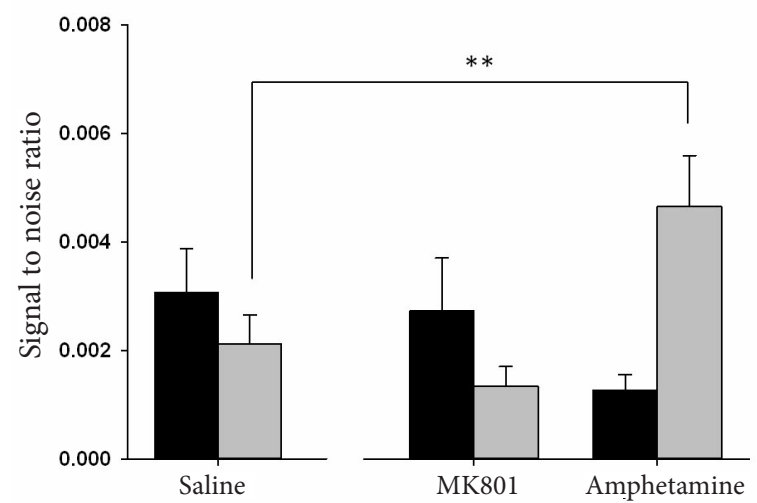

Figure 4. Time frequency analysis of the EEG phase locked to the auditory stimulus is shown for (A) baseline gamma power, (B) evoked gamma power, and (C) gamma signal to noise ratio. MK801 caused an increase in baseline gamma power in WT and BRAT rats. Amphetamine did not change baseline gamma power in WT but was decreased in BRAT rats. Conversely, MK801 had no effect on evoked gamma power and SNR. The BRAT rats demonstrated an elevation in evoked gamma power as well as SNR $\left(\dagger \mathrm{p}<0.1,{ }^{*} \mathrm{p}<0.05,{ }^{* *} \mathrm{p}<0.001\right)$.

In this study, we intended to clarify some of the potential mechanisms which lead to the behavioral abnormalities relevant to schizophrenia observed in BRAT rats. The two dominant mechanistic theories in schizophrenia posit an increase in dopaminergic tone and a reduction in glutamatergic tone $[59,60]$. Several studies have shown an exaggerated response to dopamine agonists and NMDA antagonists in patients with schizophrenia. Using pharmacological agents we identified several behaviors and electrophysiological measures that were sensitive to dopaminergic and glutamatergic perturbation in VP deficient BRAT and/or WT rats.

\section{Response to NMDA antagonist treatment}

The behavioral response to glutamatergic perturbation was assessed using the NMDA antagonist MK801. BRAT rats did not have baseline PPI impairments, consistent with some previously published reports $[44,61]$ but inconsistent with others $[\mathbf{2 9}, \mathbf{5 4}, \mathbf{5 5}]$. This inconsistency is likely due to differences in the method of PPI measurement. For example, we previously demonstrated that BRAT rats are insensitive to alterations in prepulse intensity, but do display differences in sensitivity to prepulse interval [61]. Consistent with previous studies, MK801 caused a reduction in PPI [62] and caused socially induced USVs (Table 1). However, MK801 failed to produce a change in startle or social interactions. Interestingly, MK801 produced similar effects regardless of genotype on all the behavioral measures tested, suggesting that the behavioral deficits manifested in BRAT rats are not dependent on NMDA signaling. Additionally, MK801 treatment was also used to determine ERP response to glutamatergic challenge in BRAT rats. MK801 treatment induced a reduction in N40 amplitude and an increase in baseline gamma power with no difference found with evoked gamma power and gamma SNR (Table 1). Consistent with behavioral evidence, MK801 induced similar ERP changes in both WT and BRAT rats.

Table 1. Summary of MK801-induced behavioral and ERP effects.

\begin{tabular}{llll}
\hline MK801 & & WT & BRAT \\
\hline Behavior & Startle & -- & -- \\
& PPI & $\downarrow$ & $\downarrow$ \\
& Social & -- & -- \\
& USV & $\downarrow$ & $\downarrow$ \\
ERP & N40 & $\downarrow$ & $\downarrow$ \\
& BL & $\uparrow$ & $\uparrow$ \\
& Evoked & -- & -- \\
& SNR & -- & -- \\
\hline
\end{tabular}

The data presented in this study indicate a limited modulatory role on PPI, social interaction, and ERPs between the NMDA system and VP. Previous reports have demonstrated that VP signaling does not alter NMDA or kainate induced HPA activation [63]. However, the experiments done in this study may not have been predictive of the complex interplay between VP and NMDA. For example, others have observed that MK801 administration reduces expression of VP in amygdala and VP analogs ameliorate MK801-induced social 
deficits and hyperlocomotion $[25,64]$.

\section{Response to dopamine agonist treatment}

The relationship between VP deficiency in BRAT rats and the dopaminergic system was established using the indirect dopamine agonist amphetamine. In contrast to MK801, the effects of amphetamine on the behaviors tested were highly dependent on genotype. In the WT rats, amphetamineinduced behavioral changes included reductions in PPI, social interactions, as well as socially induced USVs. However, there was no difference observed with startle. Conversely in BRAT rats, amphetamine induced a reduction in startle and an increase in socially induced vocalizations. However, there were no differences in amphetamine-induced behavioral changes in BRAT rats on PPI or social interactions. (Table 2). The effects of amphetamine on the behavioral measures examined suggest an interaction between vasopressin and dopamine signaling. Additionally, ERPs were recorded following amphetamine administration in order to assess differential responsiveness in the dopamine system as a function of VP ablation. In line with the effects observed on behavior, amphetamine produced differential effects in the WT and BRAT rats. In WT rats, the amphetamine-induced response was limited to a qualitative reduction in evoked gamma power with no difference seen in the N40 amplitude, baseline gamma power, or gamma SNR. In contrast, amphetamine in BRAT rats produced an elevation in $\mathrm{N} 40$ amplitude, a reduction in baseline gamma power, and an increase in gamma SNR, with a qualitative increase in evoked gamma power (Table 2).

Table 2. Summary of amphetamine-induced behavioral and ERP effects.

\begin{tabular}{llll}
\hline Amphetamine & & WT & BRAT \\
\hline Behavior & Startle & -- & $\downarrow$ \\
& PPI & $\downarrow$ & -- \\
& Social & $\downarrow$ & -- \\
ERP & USV & $\downarrow$ & $\uparrow$ \\
& N40 & -- & $\uparrow$ \\
& BL & -- & $\downarrow$ \\
& Evoked & -- or $\downarrow$ & $\uparrow$ \\
& SNR & -- & $\uparrow$ \\
\hline
\end{tabular}

Interestingly, decreased levels of dopamine and dihydroxyphenylacetic acid (dopamine metabolite) in the frontal cortex have previously been reported in these rats, providing evidence for a reduction in dopamine receptors in the frontal cortex [44], and a possible explanation for the results observed here. Furthermore, D2 receptor binding in the nucleus accumbens shell and dorsomedial caudate are significantly higher in BRAT compared with LE rats [29]. Data in the current study, as well as previously published reports, provide evidence suggesting that BRAT rats are highly sensitive to a dopaminergic perturbation.

\section{Limitations}

VP has many important functions including neuromodulation of the HPA axis and the stress response [65]. The BRAT rats have altered HPA axis function that provides an alternative mechanism for the observed phenotypes. Additionally, perinatal and adolescent stressors are risk factors for schizophrenia [66]. Post-mortem studies also indicate that VP and HPA-axis associated constituents such as cortisol are differentially expressed in the pituitary gland of schizophrenia patients [67]. This study did not account for cortisol levels and therefore the effects of the HPA axis alteration were not accessed. Another limitation was the use of single doses for MK801 and amphetamine to assess the effects of NMDA antagonist and dopamine agonist respectively in conjunction with VP deficiency. Nonetheless, the doses used were consistent with those used in rats to elicit deficits in PPI, a consistent endophenotype found in rat models of schizophrenia [68-70]. Furthermore, the doses chosen produced similar increases in locomotor activity, a gross measure of response to the pharmacological intervention. However, since single doses were used in this study it is difficult to make any definitive conclusions on the dose response relationship between dopamine agonist/NMDA antagonist activity and vasopressin deficiency.

\section{Conclusion}

Although glutamatergic and dopaminergic signaling are proposed to be involved in schizophrenia, the relat ionship between vasopressin and these systems has been unclear. We demonstrate through several behavioral and electrophysiological measures that there is limited evidence to support a relationship between VP and NMDAmediated glutamate signaling. Although there are behavioral abnormalities consistent between hypoglutamatergic function models and VP deficient BRAT rats, these impairments are likely independent of specific deficits in NMDA-mediated glutamate signaling. Conversely, these same measures indicate a significant interaction between VP and dopamine signaling. However, the mechanism through which dopamine and VP interact has yet to be determined. Future studies will address potential regional and molecular mechanisms for the observed differences in sensitivity to alterations of DA signaling.

\section{Competing interests}

The authors declare that they have no competing interests.

Authors' contributions

\begin{tabular}{|l|c|c|c|c|c|c|c|c|c|}
\hline Authors' contributions & REL & LA & ENB & JDS & MC & AC & VT & REF & SJS \\
\hline Research concept and design & $\checkmark$ & -- & -- & -- & -- & -- & -- & -- & $\checkmark$ \\
\hline Collection and/or assembly of data & $\checkmark$ & $\checkmark$ & $\checkmark$ & $\checkmark$ & $\checkmark$ & $\checkmark$ & $\checkmark$ & -- & $\checkmark$ \\
\hline Data analysis and interpretation & $\checkmark$ & $\checkmark$ & $\checkmark$ & $\checkmark$ & $\checkmark$ & $\checkmark$ & $\checkmark$ & $\checkmark$ & $\checkmark$ \\
\hline Writing the article & $\checkmark$ & -- & -- & -- & -- & -- & -- & -- & $\checkmark$ \\
\hline Critical revision of the article & -- & -- & -- & -- & -- & -- & -- & -- & $\checkmark$ \\
\hline Final approval of article & -- & -- & -- & -- & -- & -- & -- & -- & $\checkmark$ \\
\hline Statistical analysis & $\checkmark$ & -- & -- & -- & -- & -- & -- & -- & $\checkmark$ \\
\hline
\end{tabular}


Lin et al. Journal of Psychiatry and Brain Functions 2014,

http://www.hoajonline.com/journals/pdf/2055-3447-1-3.pdf

doi: 10.7243/2055-3447-1-3

\section{Acknowledgement}

Funding for this study was provided by 5R01MH074672-06 to SJS. The current work contributed to the Ph.D. thesis of REL. As such, the authors wish to thank Drs. Chang-Gyu Hahn, Emma Meagher, and Perry Molinoff for countless hours of guidance regarding thesis design and data interpretation.

Publication history

Senior Editor: Gianluca Serafini, Sapienza University of Rome, Italy. Received: 28-Aug-2013 Final Revised: 10-May-2014

Accepted: 16-May-2014 Published: 04-Jun-2014

\section{References}

1. Avila MT, Sherr J, Valentine LE, Blaxton TA and Thaker GK. Neurodevelopmental interactions conferring risk for schizophrenia: a study of dermatoglyphic markers in patients and relatives. Schizophr Bull. 2003; 29:595-605. | Article | PubMed

2. Battle YL, Martin BC, Dorfman JH and Miller LS. Seasonality and infectious disease in schizophrenia: the birth hypothesis revisited. $J$ Psychiatr Res. 1999; 33:501-9. | Article | PubMed

3. Bennedsen BE, Mortensen PB, Olesen AV, Henriksen TB and Frydenberg M. Obstetric complications in women with schizophrenia. Schizophr Res. 2001; 47:167-75. | Article | PubMed

4. Brown AS. Exposure to prenatal infection and risk of schizophrenia. Front Psychiatry. 2011; 2:63. | Article | PubMed Abstract | PubMed Full $\underline{\text { Text }}$

5. Brown AS. The environment and susceptibility to schizophrenia. Prog Neurobiol. 2011; 93:23-58. | Article | PubMed Abstract | PubMed Full $\underline{\text { Text }}$

6. Weisbrod M, Hill H, Sauer H, Niethammer R, Guggenbuhl S, Hell D and Stassen $\mathrm{HH}$. Nongenetic pathologic developments of brainwave patterns in monozygotic twins discordant and concordant for schizophrenia. Am J Med Genet B Neuropsychiatr Genet. 2004; 125B:1-9. | Article | PubMed

7. Graff-Guerrero A, Mizrahi R, Agid O, Marcon H, Barsoum P, Rusjan P, Wilson AA, Zipursky $R$ and Kapur $S$. The dopamine $D 2$ receptors in high-affinity state and D3 receptors in schizophrenia: a clinical [11C]-(+)PHNO PET study. Neuropsychopharmacology. 2009; 34:1078-86. | Article I PubMed

8. Howes OD and Kapur S. The dopamine hypothesis of schizophrenia: version III--the final common pathway. Schizophr Bull. 2009; 35:549-62. | Article | PubMed Abstract | PubMed Full Text

9. Kehrer C, Maziashvili N, Dugladze T and Gloveli T. Altered ExcitatoryInhibitory Balance in the NMDA-Hypofunction Model of Schizophrenia. Front Mol Neurosci. 2008; 1:6. | Article | PubMed Abstract | PubMed Full Text

10. Carlsson A and Lindqvist M. Effect of Chlorpromazine or Haloperidol on Formation of 3methoxytyramine and Normetanephrine in Mouse Brain. Acta Pharmacol Toxicol (Copenh). 1963; 20:140-4. | Article | PubMed

11. Creese I, Burt DR and Snyder SH. Dopamine receptor binding predicts clinical and pharmacological potencies of antischizophrenic drugs. Science. 1976; 192:481-3. | Article | PubMed

12. Delay J, Deniker $P$ and Harl JM. [Therapeutic use in psychiatry of phenothiazine of central elective action (4560 RP)]. Ann Med Psychol (Paris). 1952; 110:112-7. I PubMed

13. Seeman $P$ and Lee T. Antipsychotic drugs: direct correlation between clinical potency and presynaptic action on dopamine neurons. Science. 1975; 188:1217-9. | Article | PubMed

14. Seeman $P$, Lee T, Chau-Wong M and Wong K. Antipsychotic drug doses and neuroleptic/dopamine receptors. Nature. 1976; 261:717-9. | Article I PubMed

15. Zarifian E, Scatton B, Bianchetti G, Cuche H, Loo H and Morselli PL. High doses of haloperidol in schizophrenia. A clinical, biochemical, and pharmacokinetic study. Arch Gen Psychiatry. 1982; 39:212-5. | Article | PubMed

16. Seeman P. All roads to schizophrenia lead to dopamine supersensitivity and elevated dopamine D2(high) receptors. CNS Neurosci Ther. 2011; 17:118-32. | Article | PubMed
17. Moghaddam B and Javitt D. From revolution to evolution: the glutamate hypothesis of schizophrenia and its implication for treatment. Neuropsychopharmacology. 2012; 37:4-15. | Article | PubMed Abstract | PubMed Full Text

18. Rao TS, Kim HS, Lehmann J, Martin LL and Wood PL. Differential effects of phencyclidine (PCP) and ketamine on mesocortical and mesostriatal dopamine release in vivo. Life Sci. 1989; 45:1065-72. | Article | PubMed

19. Crane GE. Cyloserine as an antidepressant agent. Am J Psychiatry. 1959; 115:1025-6. | Article | PubMed

20. Rung JP, Carlsson A, Ryden Markinhuhta K and Carlsson ML. (+)-MK-801 induced social withdrawal in rats; a model for negative symptoms of schizophrenia. Prog Neuropsychopharmacol Biol Psychiatry. 2005; 29:827-32. | Article | PubMed

21. Marek GJ, Behl B, Bespalov AY, Gross G, Lee Y and Schoemaker H. Glutamatergic (N-methyl-D-aspartate receptor) hypofrontality in schizophrenia: too little juice or a miswired brain? Mol Pharmacol. 2010; 77:317-26. | Article | PubMed

22. Teltsh $\mathrm{O}$ et al. Oxytocin and vasopressin genes are significantly associated with schizophrenia in a large Arab-Israeli pedigree. Int J Neuropsychopharmacol. 2011; 1-11.

23. Caldwell HK, Lee HJ, Macbeth AH and Young WS, 3rd. Vasopressin: behavioral roles of an "original" neuropeptide. Prog Neurobiol. 2008; 84:1-24. | Article | PubMed Abstract | PubMed Full Text

24. Brambilla F, Bondiolotti GP, Maggioni M, Sciascia A, Grillo W, Sanna F, Latina A and Picotti GB. Vasopressin (DDAVP) therapy in chronic schizophrenia: effects on negative symptoms and memory. Neuropsychobiology. 1989; 20:113-9. | Article | PubMed

25. Matsuoka T, Sumiyoshi T, Tanaka K, Tsunoda M, Uehara T, Itoh H and Kurachi M. NC-1900, an arginine-vasopressin analogue, ameliorates social behavior deficits and hyperlocomotion in MK-801-treated rats: therapeutic implications for schizophrenia. Brain Res. 2005; 1053:131-6. | Article | PubMed

26. Ohsawa H, Kishimoto T, Shimayoshi N, Matsumura K, Tahara K, Kitera $\mathrm{K}$, Higashiura N, Noriyama Y, Matsumoto H, Hirai M and et al. Atrial natriuretic peptide and arginine vasopressin secretion in schizophrenic patients. Acta Psychiatr Scand. 1993; 88:130-4. | Article | PubMed

27. Feifel D, Melendez $G$ and Shilling PD. Reversal of sensorimotor gating deficits in Brattleboro rats by acute administration of clozapine and a neurotensin agonist, but not haloperidol: a potential predictive model for novel antipsychotic effects. Neuropsychopharmacology. 2004; 29:731-8. | Article | PubMed

28. Feifel D and Priebe K. Vasopressin-deficient rats exhibit sensorimotor gating deficits that are reversed by subchronic haloperidol. Biol Psychiatry. 2001; 50:425-33. | Article | PubMed

29. Shilling PD, Kinkead B, Murray T, Melendez G, Nemeroff CB and Feifel D. Upregulation of striatal dopamine-2 receptors in Brattleboro rats with prepulse inhibition deficits. Biol Psychiatry. 2006; 60:1278-81. | Article I PubMed

30. Brambilla F, Aguglia E, Massironi R, Maggioni M, Grillo W, Castiglioni R, Catalano $M$ and Drago F. Neuropeptide therapies in chronic schizophrenia: TRH and vasopressin administration. Neuropsychobiology. 1986; 15:114-21. | Article | PubMed

31. Stein D, Bannet J, Averbuch I, Landa L, Chazan S and Belmaker RH. Ineffectiveness of vasopressin in the treatment of memory impairment in chronic schizophrenia. Psychopharmacology (Berl). 1984; 84:566-8. | Article | PubMed

32. Guastella AJ, Kenyon AR, Alvares GA, Carson DS and Hickie IB. Intranasal arginine vasopressin enhances the encoding of happy and angry faces in humans. Biol Psychiatry. 2010; 67:1220-2. | Article | PubMed

33. Guastella AJ, Kenyon AR, Unkelbach C, Alvares GA and Hickie IB. Arginine Vasopressin selectively enhances recognition of sexual cues in male humans. Psychoneuroendocrinology. 2011; 36:294-7. | Article | PubMed

34. Albers HE. The regulation of social recognition, social communication and aggression: vasopressin in the social behavior neural network. Horm Behav. 2012; 61:283-92. | Article | PubMed

35. lager AC, Kirch DG, Bigelow LB and Karson CN. Treatment of schizophrenia with a vasopressin analogue. Am J Psychiatry. 1986; 143:375-7. | Article | PubMed

36. Phillips PA, Abrahams JM, Kelly J, Paxinos G, Grzonka Z, Mendelsohn FA and Johnston $\mathrm{Cl}$. Localization of vasopressin binding sites in rat brain by 
in vitro autoradiography using a radioiodinated V1 receptor antagonist. Neuroscience. 1988; 27:749-61. | Article I PubMed

37. Hernando F, Schoots O, Lolait SJ and Burbach JP. Immunohistochemical localization of the vasopressin $\mathrm{V} 1 \mathrm{~b}$ receptor in the rat brain and pituitary gland: anatomical support for its involvement in the central effects of vasopressin. Endocrinology. 2001; 142:1659-68. | Article | PubMed

38. Brito GN, Thomas GJ, Gingold SI and Gash DM. Behavioral characteristics of vasopressin-deficient rats (Brattleboro strain). Brain Res Bull. 1981; 6:71-5. | Article | PubMed

39. Burnard DM, Pittman QJ and Veale WL. Brattleboro rats display increased sensitivity to arginine vasopressin-induced motor disturbances. Brain Res. 1985; 342:316-22. | Article | PubMed

40. Engelmann $M$ and Landgraf R. Microdialysis administration of vasopressin into the septum improves social recognition in Brattleboro rats. Physiol Behav. 1994; 55:145-9. | Article | PubMed

41. Feifel D, Melendez G, Priebe K and Shilling PD. The effects of chronic administration of established and putative antipsychotics on natural prepulse inhibition deficits in Brattleboro rats. Behav Brain Res. 2007; 181:278-86. | Article | PubMed

42. Feifel D, Mexal S, Melendez G, Liu PY, Goldenberg JR and Shilling PD. The brattleboro rat displays a natural deficit in social discrimination that is restored by clozapine and a neurotensin analog. Neuropsychopharmacology. 2009; 34:2011-8. I Article I PubMed Abstract | PubMed Full Text

43. Frank $E$ and Landgraf $R$. The vasopressin system--from antidiuresis to psychopathology. Eur J Pharmacol. 2008; 583:226-42. | Article | PubMed

44. Cilia J, Gartlon JE, Shilliam C, Dawson LA, Moore SH and Jones DN. Further neurochemical and behavioural investigation of Brattleboro rats as a putative model of schizophrenia. J Psychopharmacol. 2010; 24:407-19. | Article | PubMed

45. Dawson R, Jr., Wallace DR and King MJ. Monoamine and amino acid content in brain regions of Brattleboro rats. Neurochem Res. 1990; 15:755-61. | Article | PubMed

46. Gandal MJ, Anderson RL, Billingslea EN, Carlson GC, Roberts TP and Siegel SJ. Mice with reduced NMDA receptor expression: more consistent with autism than schizophrenia? Genes Brain Behav. 2012; 11:740-50. | Article | PubMed Abstract | PubMed Full Text

47. Connolly PM, Maxwell C, Liang Y, Kahn JB, Kanes SJ, Abel T, Gur RE, Turetsky $\mathrm{BI}$ and Siegel SJ. The effects of ketamine vary among inbred mouse strains and mimic schizophrenia for the P80, but not P20 or N40 auditory ERP components. Neurochem Res. 2004; 29:1179-88. | Article I PubMed

48. Connolly PM, Maxwell CR, Kanes SJ, Abel T, Liang Y, Tokarczyk J, Bilker WB, Turetsky BI, Gur RE and Siegel SJ. Inhibition of auditory evoked potentials and prepulse inhibition of startle in DBA/2J and DBA/2Hsd inbred mouse substrains. Brain Res. 2003; 992:85-95. | Article | PubMed

49. Ehrlichman RS, Gandal MJ, Maxwell CR, Lazarewicz MT, Finkel LH, Contreras D, Turetsky BI and Siegel SJ. N-methyl-d-aspartic acid receptor antagonist-induced frequency oscillations in mice recreate pattern of electrophysiological deficits in schizophrenia. Neuroscience. 2009; 158:705-12. | Article | PubMed

50. Maxwell CR, Kanes SJ, Abel T and Siegel SJ. Phosphodiesterase inhibitors: a novel mechanism for receptor-independent antipsychotic medications. Neuroscience. 2004; 129:101-7. | Article | PubMed

51. Metzger KL, Maxwell CR, Liang Y and Siegel SJ. Effects of nicotine vary across two auditory evoked potentials in the mouse. Biol Psychiatry. 2007; 61:23-30. | Article | PubMed

52. Siegel SJ, Maxwell CR, Majumdar S, Trief DF, Lerman C, Gur RE, Kanes $\mathrm{SJ}$ and Liang Y. Monoamine reuptake inhibition and nicotine receptor antagonism reduce amplitude and gating of auditory evoked potentials. Neuroscience. 2005; 133:729-38. I Article I PubMed

53. Aarde SM and Jentsch JD. Haploinsufficiency of the arginine-vasopressin gene is associated with poor spatial working memory performance in rats. Horm Behav. 2006; 49:501-8. | Article | PubMed

54. Feifel $D$ and Priebe K. The effects of cross-fostering on inherent sensorimotor gating deficits exhibited by Brattleboro rats. J Gen Psychol. 2007; 134:173-82. | Article | PubMed

55. Feifel D, Shilling PD and Melendez G. Further characterization of the predictive validity of the Brattleboro rat model for antipsychotic efficacy. J Psychopharmacol. 2011; 25:836-41. | Article | PubMed

56. Gash DM, Warren PH, Dick LB, Sladek JR, Jr. and Ison JR. Behavioral modification in Brattleboro rats due to vasopressin administration and neural transplantation. Ann N Y Acad Sci. 1982; 394:672-88. | Article | PubMed

57. Jentsch JD, Arguello PA and Anzivino LA. Null mutation of the arginine-vasopressin gene in rats slows attentional engagement and facilitates response accuracy in a lateralized reaction time task. Neuropsychopharmacology. 2003; 28:1597-605. | Article | PubMed

58. Schank JC. Early locomotor and social effects in vasopressin deficient neonatal rats. Behav Brain Res. 2009; 197:166-77. | Article I PubMed

59. Kapur S. Psychosis as a state of aberrant salience: a framework linking biology, phenomenology, and pharmacology in schizophrenia. Am J Psychiatry. 2003; 160:13-23. | Article | PubMed

60. Moghaddam B. Bringing order to the glutamate chaos in schizophrenia. Neuron. 2003; 40:881-4. | Article | PubMed

61. Lin RE, Ambler L, Billingslea EN, Suh J, Batheja S, Tatard-Leitman V, Featherstone RE and Siegel SJ. Electroencephalographic and early communicative abnormalities in Brattleboro rats. Physiol Rep. 2013; 1:e00100. | Article | PubMed Abstract | PubMed Full Text

62. Kesby JP, Burne TH, McGrath JJ and Eyles DW. Developmental vitamin D deficiency alters MK 801-induced hyperlocomotion in the adult rat: An animal model of schizophrenia. Biol Psychiatry. 2006; 60:591-6. I Article I PubMed

63. Zelena D, Langnaese K, Domokos A, Pinter O, Landgraf R, Makara GB and Engelmann $\mathrm{M}$. Vasopressin administration into the paraventricular nucleus normalizes plasma oxytocin and corticosterone levels in Brattleboro rats. Endocrinology. 2009; 150:2791-8. | Article | PubMed

64. Matsuoka T, Tsunoda M, Sumiyoshi T, Takasaki I, Tabuchi Y, Seo T, Tanaka $\mathrm{K}$, Uehara $\mathrm{T}$, Itoh $\mathrm{H}$, Suzuki $\mathrm{M}$ and Kurachi M. Effect of MK-801 on gene expressions in the amygdala of rats. Synapse. 2008; 62:1-7. | Article | PubMed

65. Landgraf R. The involvement of the vasopressin system in stress-related disorders. CNS Neurol Disord Drug Targets. 2006; 5:167-79. | Article | PubMed

66. Malaspina D, Corcoran C, Kleinhaus KR, Perrin MC, Fennig S, Nahon D, Friedlander $\mathrm{Y}$ and Harlap $\mathrm{S}$. Acute maternal stress in pregnancy and schizophrenia in offspring: a cohort prospective study. BMC Psychiatry. 2008; 8:71 | Article | PubMed Abstract | PubMed Full Text

67. Krishnamurthy D, Harris LW, Levin Y, Koutroukides TA, Rahmoune H, Pietsch S, Vanattou-Saifoudine N, Leweke FM, Guest PC and Bahn S. Metabolic, hormonal and stress-related molecular changes in postmortem pituitary glands from schizophrenia subjects. World $\mathrm{J}$ Biol Psychiatry. 2013; 14:478-89. | Article | PubMed

68. Narayanan S, Wallace L and Uretsky N. Spontaneous and drugstimulated locomotor activity after the administration of pertussis toxin into the ventral tegmental area. J Psychiatry Neurosci. 1996; 21:172-80. | PubMed Abstract | PubMed Full Text

69. Gaytan O, Swann AC and Dafny N. Effects of amphetamine at the beginning of the light cycle on multiple indices of motor activity in the rat. Eur J Pharmacol. 1996; 300:1-8. | Article | PubMed

70. Blaszczyk JW, Werka T and Sadowski B. Acoustic startle and disruption of prepulse inhibition by dizocilpine in selectively bred mice. Acta Neurobiol Exp (Wars). 2010; 70:271-8. | Pdf | PubMed

\section{Citation:}

Lin RE, Ambler L, Billingslea EN, Suh J, Cho

M, Ciacci A, Tatard-Leitman V, Featherstone

RE and Siegel SJ. Differential sensitivity of the

Brattleboro rat to glutamatergic and dopaminergic

perturbation. J Psychiatry Brain Funct. 2014; 1:3.

http://dx.doi.org/10.7243/2055-3447-1-3 